\title{
La Colectoría de España en el siglo XVI: los mecanismos de transfe- rencia monetaria entre España y Roma (cambios y créditos)
}

\section{Juan Manuel Carretero Zamora}

Universidad Complutense de Madrid

RESUMEN: $\quad$ Las tensiones estructurales entre el nuncio-colector y la Corona española fueron especialmente intensas en el ámbito de la gestión de las rentas pontificias. A lo largo del siglo XVI, la Colectoría de España -institución encargada de percibir las rentas de los espolios de los obispos fallecidos y el producto de los frutos de las sedes vacantes-, tendió a fortalecer sus funciones, por un lado, mediante la definición del territorio de actuación y de la creación de cauces seguros y eficaces para la transferencia de los capitales generados por las rentas pontificias de España en beneficio de la Cámara Apostólica de Roma. Ello fue debido, como explica el profesor Carretero Zamora basándose en fondos del Archivio di Stato di Roma y del Archivio Segreto Vaticano, a la inclusión de la Colectoría en los eficientes mercados de letras de cambio entre España y Roma desde comienzos del siglo XVI, así como, a partir de la segunda mitad de la centuria, con la consolidación de la figura del tesorero general de la Colectoría y su vinculación con la banca próxima a la Cámara Apostólica en Roma, de origen genovés y que también controlaba el negocio del arrendamiento de los frutos de las vacantes episcopales castellanas. Financieros de los que saldrán los sucesivos depositarios generales, encargados de proporcionar liquidez a las cuentas pontificias y créditos casi ilimitados a la Cámara Apostólica sobre los rendimientos de las rentas españolas.

\section{Palabras ClaVE: Roma; Siglo XVI; Colectoría de España; Banca genovesa; Letras de cambio; Crédito pontificio.}

The Spanish “Colectoría” in the XVI ${ }^{\text {th }}$ Century: The Monetary Transfers Between Spain and Rome 
ABSTRACT: The problems between the Papal nuncio and the Spanish Crown were particularly serious in the field of the Papal revenues. During the sixteenth century, the "Colectoría” of Spain, a commitee charged with the task of collecting the revenues of the vacant bishoprics, increased its importance through improvements in the methods used to transfer to Rome the revenues collected by the Vatican from Spain. This was possible thanks to the massive use of letters of exchange between Spain and Rome since the beginnings of the sixteenth century and to the growing importance of the Treasurer of the Colectoría. The Treasurers were usually well connected with the big genoese banking houses and from this group emerged the so called "Depositarios", who used the revenues collected from Spain to support the Vatican Treasury.

\section{KEY WORDS: Rome; Sixteenth Century; Genoese Banks; Letters of Exchange; Papal Credit.}

A fines del siglo XVI la Colectoría de España había logrado adquirir una entidad y estabilidad institucionales impensables sólo cien años antes, y ello con independencia de ciertos males crónicos en su relación con las instancias políticas (Consejo Real) y jurisdiccionales (corregidores, Chancillerías y el propio Consejo en tanto órgano de justicia) de la monarquía de los Habsburgo. Estas tensiones estructurales entre el nuncio-colector como representante de los intereses de la Cámara Apostólica de Roma y la Corona fueron especialmente intensas en dos ámbitos: en primer lugar, en los continuos enfrentamientos jurisdiccionales entre el colector y sus subcolectores con las autoridades civiles y eclesiásticas españolas a la hora de la gestión de las rentas pontificias (sobre todo, en los frutos de las vacantes y en los espolios). En segundo término, por las aspiraciones del Consejo Real en obtener de Roma la separación de los oficios de nuncio y de colector en dos realidades institucionales claramente diferenciadas, siempre con la finalidad de debilitar la posición política de la Colectoría.

No obstante todo esto, la Colectoría de España en el tránsito del siglo XVI al XVII había superado ciertas épocas de enorme tensión con la Corona (caso, por ejemplo, de la gestión de las enormes rentas generadas durante la «vacante» del arzobispo Carranza) ${ }^{1}$ que, en definitiva, habían servido para depurar las funciones de los nuncios-colectores. Y en este punto, convendría recordar

1 (A)rchivio (S)egreto (V)aticano, Segretaria di Stato, Spagna, 21, donde consta una relación de ingresos de los frutos del arzobispado de Toledo. Una parte de dichos ingresos fue utilizada en préstamos a concejos (caso de Toledo con 100000 ducados y de Madrid con otros 25000) y a instituciones eclesiásticas de la ciudad de Toledo (Compañía de Jesús, monasterio de S. Pedro Mártir, monjas de la Madre de Dios, etc.), así como de la jurisdicción arzobispal: iglesia colegial de Alcalá de Henares, monasterio de Santo Domingo de Guadalajara, Santo Domingo el Real de Madrid y las monjas de la villa de Pinto. 
que las Colectorías habían surgido a lo largo de la Edad Media, erigiéndose en unas instituciones esenciales para la cohesión de la Cristiandad y, sobre todo, como vehículo fortalecedor del poder de los pontífices de Roma.

El innegable éxito político e institucional del pontificado ante las monarquías cristianas medievales no pudo extrapolarse plenamente en el terreno de la eficacia hacendística. Así, en las Coronas y reinos de España — como en general en el resto de las monarquías de Europa- las Colectorías pontificias vieron mermada su eficacia por una serie de fenómenos, entre los que cabe significar, la inicial indefinición jurídica de sus funciones, propiciando un sinfín de conflictos jurisdiccionales con las monarquías, la ineficacia en la gestión de las rentas pontificias, dando lugar (especialmente en el tránsito entre el siglo XV y el XVI) a pobrísimos resultados económicos para la Cámara Apostólica de Roma y, por último, la inexistencia de cauces financieros eficaces para el traslado de las cantidades recaudadas en los reinos de España hacia la hacienda central pontificia en Roma. En síntesis, a lo largo del siglo XVI (sobre todo a partir del reinado de Carlos V tras el Saco de Roma) la Colectoría de España tendió a fortalecer sus funciones a partir de los siguientes fenómenos:

$1^{\circ}$. La definición del ámbito territorial de actuación (especialmente con la consolidación de las subcolectorías como unidades básicas de gestión), así como la fijación de los derechos económicos pontificios en los reinos de España mediante pactos con la Corona.

$2^{\circ}$. La determinación de las rentas pontificias adscritas en exclusiva a la gestión de los colectores (frutos de las vacantes, espolios episcopales², censos sobre monasterios y algunas décimas residuales), así como su expansión cuantitativa. Por ejemplo, hacia 1531-1538 la renta neta de las sedes vacantes de España había observado un notable incremento respecto principios del siglo XVI, fruto de las negociaciones del nuncio-colector Giovanni Poggio:

2 Frente a la teoría de que los espolios no ofrecieron beneficios significativos para la Cámara Apostólica, considero por el contrario que constituyó una fuente saneadísima de ingresos para Roma. Por ejemplo, el espolio del cardenal primado don Juan de Tavera en 1545 produjo un ingreso neto en las arcas romanas de 16000 ducados. En las cuentas de la Colectoría (A)rchivio di (S)tato di (R)oma, Camerale I, Collettorie, 1198, 3C) se asentó: «Primieramente, da conto et ragione como lo Reverendisimo don Giovanni Tavera, arcivesco de Toledo, muori in Vagliadolid a di primo di agosto 1545, et fece testamento, in vertu della licenza et faculta che havena di possere testare et disponere delle dua terza de suoi beni et spoglio. Si fece inventario di tutto, et venendosi sopra dicio in differenza et controversia con si heredi et testamentarii del Reverendisimo arcivesco et cardinale, et dipoi a termini di compositione et concordia, fu consultato prima con Nostro Signore et col Reverendisimo cardinale Santafiore, camorlengo. Per volunta de quali, fu composito tutto l'interesse che havena la Camara Apostolica sopra detto spoglio per sedecimila ducati de iguali detrattine, mille et seicento per la decima appartenente al collettore generale et succollettore, restano netti alla camara ducati quattordici mila et quattrocento, et di tanti si fa carico il monsignore nuntio in questa partita: Introito, 16.000. Decima, 1.600. Neti, 14.400 ducati». 
TABLA 1

\begin{tabular}{|c|c|c|c|}
\hline CUENTAS AÑO & SEDE VACANTE & INGRESO BRUTO ${ }^{3}$ & INGRESO NETO \\
\hline 1531-1532 & Coria & no consta & 1254.7.13 \\
\hline $1531-1532$ & Salamanca & 618.16 .15 & 557.0 .0 \\
\hline 1531-1532 & Huesca & 2206.0 .0 & 100.3.0 \\
\hline 1531-1532 & Burgos & no consta & 12034.4 .22 \\
\hline $1531-1532$ & Ávila & no consta & 2283.1 .23 \\
\hline 1531-1532 & Urgel & 1567.7 .20 & 272.4 .0 \\
\hline 1531-1532 & Salamanca & no consta & 2000.0 .0 \\
\hline $1531-1532$ & Lugo & 826.7 .22 & 826.7.22 \\
\hline fines de $1532^{4}$ & Coria & 884.4 .25 & 884.4 .25 \\
\hline fines de 1532 & Salamanca & 4618.10 .0 & 800.0 .0 \\
\hline fines de 1532 & Canarias & 400.0 .0 & 360.0 .0 \\
\hline 1533 & Ávila & más de 4.300 ducs. & 216.9.11 \\
\hline 1533 & Ciudad Rodrigo & no consta & 133.1.22 \\
\hline 1533 & Oviedo & no consta & 2000.0 .0 \\
\hline 1533 & Lugo & no consta & 1435.0 .0 \\
\hline 1533 & Zaragoza & no consta & 3600.0 .0 \\
\hline 1533 & Gerona & 833.0 .0 & 750.0 .0 \\
\hline 1533 & Mallorca & no consta & 1000.0 .0 \\
\hline 1534 & Lugo & no consta & 816.7 \\
\hline 1534 & Gerona & no consta & 1858.7.22 \\
\hline 1534 & Zaragoza & no consta & 1125.8 .30 \\
\hline 1534 & Tortosa & 1000.0 .0 & 900.0 .0 \\
\hline $1535-1536$ & Tortosa & no consta & 1500.0 .0 \\
\hline $1535-1536$ & Toledo & 9000.0 .0 & 8100.0 .0 \\
\hline $1535-1536$ & Santiago & 1500.0 .0 & 1350.0 .0 \\
\hline $1535-1536$ & Burgos & 11218.0 .0 & 4550.0 .0 \\
\hline $1535-1536$ & Palencia & 8500.0 .0 & 3147.0 .0 \\
\hline $1535-1536$ & Jaén & 8500.0 .0 & 5898.0 .0 \\
\hline $1535-1536$ & Canarias & 4500.0 .0 & 3174.0 .0 \\
\hline $1535-1536$ & Tarazona & 5160.0 .0 & 3768.0 .0 \\
\hline $1535-1536$ & Tortosa & 3300.0 .0 & 2970.0 .0 \\
\hline $1537-1538$ & Burgos & 9000.0 .0 & 5647.0 .0 \\
\hline $1537-1538$ & Palencia & no consta & 1215.3 .0 \\
\hline $1537-1538$ & Jaén & 8500.0 .0 & 3031.0 .0 \\
\hline
\end{tabular}

3 Todas las cuentas van expresadas en este cuadro según el módulo «ducados.reales. maravedíes».

4 En concreto, desde 1 de septiembre hasta 31 de diciembre de 1532 (A.S.R., Camerale I, Collettorie, 1198, 2 B, ff. 10-13). 


\begin{tabular}{c|c|c|c} 
CUENTAS AÑO & SEDE VACANTE & INGRESO BRUTO $^{5}$ & INGRESO NETO $^{\text {ING }}$ \\
\hline $1537-1538$ & Burgos & 2410.0 .13 & 2169.1 .0 \\
$1537-1538$ & Salamanca & 1916.4 .0 & 893.2 .0 \\
$1537-1538$ & Cuenca & 3561.0 .10 & 1831.6 .0 \\
$1537-1538$ & Valencia & 2321.1 .0 & 2321.1 .0 \\
$1537-1538$ & Canarias & 2400.0 .0 & 1200.0 .0 \\
\hline
\end{tabular}

$3^{\circ}$. La consolidación de la organización administrativa de la Colectoría como órgano centralizado (colector, subcoletor general, subcoletores territoriales, tesorero, notarios apostólicos, letrados, etc.) y la depuración de los métodos de exacción de las rentas (optimización de los sistemas de gestión mediante arrendamiento en el caso de las vacantes, y agilización de los acuerdos con la Corona y los familiares en el modelo de los espolios).

$4^{\circ}$. La creación de cauces seguros y eficaces para la transferencia de los capitales generados por las rentas pontificias de España en beneficio de la Cámara Apostólica de Roma. Ello fue posible, como veremos más adelante, debido a la inclusión de la Colectoría en los mercados de letras de cambio entre España y Roma desde comienzos del siglo XVI, así como, a partir de la segunda mitad de la centuria, con la consolidación de la figura del tesorero general de la Colectoría y su vinculación con la banca próxima a la Cámara Apostólica en Roma.

$5^{\circ}$. En definitiva, la vinculación de las rentas de la Colectoría con las necesidades de crédito de la Cámara Apostólica romana a través del sistema bancario italiano asentado, tanto en España, como en Italia.

¿Cómo era a grandes rasgos la estructura jurisdiccional y funcional de la Colectoría de España durante el siglo XVI? El término Colectoría de España fue acuñado en Roma por los gestores de la Cámara Apostólica; de hecho, toda la documentación desde la Edad Media hasta el siglo XVIII insiste invariablemente en dicho término general «de España». El uso de este término provenía de una realidad institucional: la Colectoría de España era una jurisdicción única que aparecía ya plenamente consolidada en época de los Reyes Católicos, sobre todo a partir de los pontificados de Alejandro VI Borgia y Julio II della Rovere. Su jurisdicción se extendía sobre todos los arzobispados y obispados de las Coronas de Castilla y de Aragón, los reinos de Navarra y de Granada, así como ciertos derechos (singularmente los espolios) del obispado de Canarias (aunque casi siempre en litigio con la Corona y los familiares de los obispos difuntos).

5 Todas las cuentas van expresadas en este cuadro según el módulo «ducados.reales. maravedíes». 
Asimismo, en la transición del siglo XV al XVI se consolidó la costumbre de que el oficio de colector general en España quedará vinculado al titular de la nunciatura. Esta tendencia a la identidad de oficios — sólo alterada en algún caso excepcional - se consolidó tras el Saco de Roma, cuando el emperador Carlos y el papa Clemente VII Médicis establecieron una serie de acuerdos para definir el ámbito de actuación de la Colectoría. Fue en esta época, en torno a 1532 y 1540, en la que quedó definitivamente consolidado el cargo de colector general, así como sus privilegios jurisdiccionales en todos los reinos de España ${ }^{6}$. Esta labor fue obra casi personal del nuncio monseñor Poggio, obispo de Tropea, verdadero creador de la moderna Colectoría de España7. Poggio, antes de venir a España, había desarrollado importantes funciones en la Cámara Apostólica de Roma, por lo que era un verdadero especialista en temas de hacienda pontificia; no casualmente, Poggio culminó su carrera eclesiástica en Roma como tesorero general de la Cámara Apostólica y cardenal de la curia ${ }^{8}$.

Ahora bien, desde la perspectiva de los intereses de la Corona, esa vinculación entre la nunciatura y la colectoría nunca fue bien admitida porque otorgaba poder suplementario a las actuaciones del colector general, especialmente cuando surgían pleitos ante los tribunales de la monarquía, o bien importantes desacuerdos entre la Cámara Apostólica de Roma y el propio Consejo Real en la determinación de los frutos de vacantes y de los espolios. Ello fue evidente, por ejemplo, en las enormes tensiones desatadas ente Madrid y Roma a la hora de determinar quién debía gestionar los ingresos del arzobispado de Toledo durante la prisión de Carranza: ¿el gobernador nombrado por la Corona o el colector del Papa?

Esto explica que en época de Felipe II y de Felipe III surgiera, sobre todo en el seno del Consejo de Castilla, el debate tendente a la limitación de los poderes excesivos del nuncio-colector, diferenciando ambos cargos y solicitando de Roma que fueran ejercidos por personas diferentes. Desde la perspectiva de la monarquía no era lo mismo pleitear con un colector que, a su vez, era el nuncio del Papa, que con un colector carente de los poderes políticos que otorgaba la Nunciatura de Madrid. Por la misma razón, en sentido opuesto, estas aspiraciones del rey católico en limitar los poderes de los colectores siempre contaron con la oposición de Roma (especialmente del car-

6 ASV, Camera Apostolica, Diversa Cameralia, 88, I, ff. 57v-58r, breve de Clemente VII a la emperatriz Isabel de Portugal (Roma, 18 de febrero de 1531) en el que se indica que no se perturbe la acción del colector en asuntos de espolios y vacantes.

7 Sobre esta Colectoría en manos de Poggio véase CARRETERO ZAMORA, LXXVIII (Buenos Aires, 2004) 103-135.

8 Creado cardenal con el título de Santa Anastasia por Julio III del Monte el 20 de noviembre de 1551. 
denal camerario, esto es, del responsable de la Cámara Apostólica) y, más en concreto, de los mismos nuncios en España, reacios a perder, tanto el poder jurisdiccional que les otorgaba la Colectoría, como sobre todo sus pingües beneficios (en torno al diez por ciento de los ingresos brutos). El debate quedó definitivamente zanjado a comienzos del siglo XVII al ser promocionado al cardenalato Decio Carafa, nuncio en España, que era un furibundo defensor de las tesis de una nunciatura fuerte en Madrid, mediante la vinculación en una sola persona de las funciones de la Nunciatura y de la Colectoría. Su informe al cardenal Escipión Borghese (nepote de Pablo V Borghese) fue decisivo para echar por tierra las aspiraciones de Felipe III y del Consejo Real ${ }^{9}$.

También durante ese periodo como nuncio-colector de Giovanni Poggio quedó definitivamente centralizada la recaudación de las rentas pontificias españolas. No obstante, es más que probable que la centralización de las decisiones de la Colectoría se encontrara muy avanzada desde comienzos del siglo XVI. Como ya se ha indicado, la clave fue la vinculación desde inicios del siglo XVI de los negocios de la Colectoría con los factores y agentes que las grandes casas bancarias de Italia habían ubicado en Castilla y Aragón (sobre todo en los centros financieros de Medina del Campo, Villalón, Medina de Rioseco y, a finales de la centuria, en Barcelona).

De igual manera, desde la llegada de monseñor Poggio a España quedó definitivamente establecido el sistema de arrendamiento de los frutos de las sedes vacantes. Por lo común — según la documentación manejada — los arrendamientos se efectuaron siempre por el sistema de adscripción directa, bien a castellanos y aragoneses solventes en el negocio, bien preferentemente a italianos vinculados con las casas bancarias que habitualmente ofrecían créditos u otro tipo de operaciones financieras con la Cámara Apostólica en Roma. La nómina de algunos arrendadores del periodo 1529-1546 sintetiza bien lo que vengo subrayando:

9 ASV, Fondo Borghese, serie I, 950, f. 325, el cardenal nepote Scipio Borghese le pidió su parecer acerca de la separación de la Nunciatura y la Colectoría: «Don Francesco de Castro [cardenal en la misma promoción de 1611 que Decio Carafa] ha detto a nuestro signore che il re desidera per molte giuste cause che si seperi il carico della nunciatura da quello del collettore dellli spogli. Su Santità gli ha resposto che por cause non men giuste Papa Clemete, santa memoria, riuni la Collettoria alla nuntiatura». Decio Carafa, siguiendo la opinión de Roma, se mostró opuesto a separar la Nunciatura de la Colectoría; el cardenal nepote Borghese en carta a Carafa (Roma, 1 de noviembre de 1611) lo confirma: "Il parere de V.S. ilustrísima che non si debba separare la Collettoria dalla Nunciatura è giunto opportunamente». 
TABLA 2

\begin{tabular}{l|c|c|c}
\hline \multicolumn{1}{c|}{ SEDE ARRENDADA } & ARRENDADORES & VECINDAD & NACION \\
\hline Coria (1529) & J. Brizzi y F. Tedaldi & Valladolid & Génova \\
Zaragoza (1531) & Agostino de S. Stefano & no consta & Génova \\
Burgos (1536) & Bernabé de Grimaldo y & Valladolid & Génova \\
Calahorra (1541) & Diego Navarro & no consta & -- \\
Lérida (1542) & Guillermo Saporta & ¿Zaragoza? & Aragón \\
Salamanca (1544) & Juan Hdez. de Paredes & Valladolid & Castilla \\
Canarias (1545) & Juan de Ortega & Valladolid & Castilla \\
Santiago (1546) & Rodrigo Calderón & & Castilla \\
Varios obispados & Juan Hdez. de Paredes & Valladolid & Castilla \\
\hline
\end{tabular}

Esta tendencia se mantendrá con el paso del tiempo, y a comienzos del siglo XVII la estructura del sistema de arrendamiento se mantendrá incólume: arrendadores españoles ${ }^{11}$ y genoveses, frecuentemente asociados entre sí en el

10 Grimaldo y Salvago eran agentes de Ansaldo de Grimaldo, depositario general de la Cámara Apostólica en Roma.

11 El potencial de los arrendadores españoles se incrementó notablemente desde fines del siglo XVI aprovechando la ruptura de la hegemonía que habían mantenido los italianos (singularmente los genoveses). Por ejemplo, la vacante del poderoso cardenal-arzobispo de Sevilla Niño de Guevara fue negociada por un sevillano, aunque quizá de ascendencia italiana (Juan Francisco Ponzón), por casi doce millones de maravedíes; el asiento de esta operación de arrendamiento en ASR, Camerale I, Collettorie, 1200, expte. M, Cuentas de monseñor Decio Caraffa, arçobispo de Damasco, nunçio y colector general en España, 1607-1611: «Sevilla, segundo arrendamiento, 1610. Juan Françisco Ponçón, administrador de la vacante del arçobispado de Sevilla por muerte y fin del cardenal D. Fernando Niño de Guevara, arçobispo que fue de la dicha çiudad, deve l`arrendamiento de la dicha vacante por un año, o la rata dél por el tiempo que durare, a respecto de sesenta y dos mill y quinientos ducados de oro al año. Arrendádale monseñor ilustrísimo Caraffa en 19 de octubre de 1610 años, y se obligó pagar lo que importase en tres pagas, como por la obligaçión ante Gaspar de León, escrivano público de Sevilla, ratificada en Madrid por su señoría illustrísima ante Juan de Obregón, notario de la Cámara, en 26 de octubre de 1610 años. Vacó el dicho arçobispado el 8 de henero de 1609 años, inclusive, y duró hasta los 4 de julio del mesmo año, esclusive que fue proveido por Su Santidad en Roma el nuevo arçobispo; de manera que hubo de vacante çiento y setenta y siete días que, a respecto de los 62.500 ducados y 1/3 valutados a 375 maravedíes cada uno, que valen 23.437.500 maravedíes, bienen cada día 62.212 maravedíes y $1 / 3$, que en los 177 días haçen la suma de onçe quentos y treçientos y sesenta y çinco mill y quinientos y ochenta maravedíes ${ }^{11}$; y tanto deve haver la Cámara: 11.865 .580 maravedíes». 
negocio de los frutos de vacantes ${ }^{12}$. En definitiva, hasta fines del siglo XVI los mejores arrendamientos se reservaron a los italianos (genoveses, florentinos, sieneses y luqueses) vinculados a las operaciones de crédito y arrendamiento de rentas de los Estados Pontificios. Los más beneficiados fueron, sin duda, los agentes italianos dependientes de los negocios de los depositarios generales de la Cámara Apostólica en Roma; estos depositarios generales eran siempre laicos y necesariamente cabeza de una solvente casa bancaria (por lo común genovesa). Un buen ejemplo sería la compañía bancaria del genovés Ansaldo de Grimaldo, depositario del Papa Clemente VII Médicis en 1532 y, no casualmente, principal banquero en ese momento del emperador Carlos V. La red de negocios de los Grimaldo en la Corona de Castilla era enorme y se remontaba cuando menos a la época de los Reyes Católicos; ello da coherencia al fenómeno de que fueran los agentes y factores de Ansaldo de Grimaldo los primeros beneficiarios del mercado de arrendamiento de vacantes de la Colectoría, así como uno de los grupos más dinámicos en el negocio de letras de cambio entre Castilla y Roma desde comienzos del siglo XVI, como veremos enseguida.

\section{EL MERCADO DE LETRAS DE CAMBIOS ENTRE CASTILLA Y ROMA A COMIEN- ZOS DEL SIGLO XVI}

Las series documentales cuantitativas referidas a las cuentas de la Colectoría de España a comienzos del siglo XVI son escasas y fragmentarias, aunque poseemos una excelente serie ${ }^{13}$ que comprende las liquidaciones correspon-

12 Un buen ejemplo de este tipo de asociación en ibidem, «Cartajena, 1607 años. Octavio Spínola, administrador de la vacante de Cartajena por muerte de D. Alonso Coloma, obispo que fue, deve l`arrendamiento de la dicha vacante el tiempo que durare a raçón de quinçe mill ducados de a 375 maravedies cada uno. Arrendádole monseñor ilustrísimo Caraffa en 7 de setiembre de 1607 años, como por los papeles ante Maçía González, notario pareçe. Vacó el dicho obispado en 21 de abril de 1606, en tiempo del cardenal ilustrísimo Melino; y estuvo arrendado por un año a Françisco Díes de Soto y Octavio Spínola en 17.000 ducados castellanos. Y después lo volvió a arrendar monseñor ilustrísimo Caraffa al dicho Spínola solo, como arriba de a dicho; y estuvo vacante çiento y catorze días, desde los 21 de abril de 1607 años, enclusive, hasta los 13 de agosto del mismo año, esclusive, que fue proveído por Su Santidad en Roma en D. Françisco Martínez. Que a raçón de los 15.000 ducados, bienen a 15.411 maravedíes cada día; que en todo haçen la suma de un quento y seteçientos y çinquenta y seis mill y ochoçientos y çinquenta maravedíes; haver la Cámara Apostólica: 1.756.850 maravedíes».

13 ASR, Camerale I, Collettorie, 1197, 4. Hay numerosas referencias fragmentarias a la Colectoría de España en el Archivio Segreto Vaticano. Por ejemplo, algunos apuntes contables de 1520 en ASV, Camera Apostolica, Diversa Cameralia, arm. 33, 31, así como en general en la sección de Registros Vaticanos de los pontificados de Julio II della Rovere, León 
dientes a los años 1506-1512 presentadas por el nuncio-colector Giovanni Ruffo di Teodole ${ }^{14}$ en 1513 ante la Cámara Apostólica del Papa León X Médicis. En concreto, durante este periodo de 1506 a 1512 las cuentas de la Colectoría asentaron al menos unos ingresos de 26,4 millones de maravedíes, de los que 22,4 fueron remitidos a Roma mediante el sistema de letras de cambio ${ }^{15}$. Más importante a nuestro propósito es el conocimiento de la estructura de la data; en efecto, las decenas de apuntes contables nos permiten rastrear los mecanismos de transferencia del dinero desde la Colectoría de España hasta su recepción por los oficiales de la Cámara Apostólica en Roma.

Antes de entrar en el análisis del mercado de letras de cambio erigido en torno a la Colectoría, convendría subrayar que del análisis de estas cuentas cabe inferir que las relaciones financieras entre España e Italia a comienzos del siglo XVI había alcanzado una densidad quizá superior a la que venimos suponiendo, que no era escasa ${ }^{16}$. En efecto, el grado de penetración de los italianos en el negocio del arrendamiento de los frutos de las vacantes episcopales de Castilla era a comienzos del siglo XVI enorme. No casualmente, los arrendadores privilegiados por el nuncio-colector fueron siempre italianos avecindados en Valladolid (esto es, próximos a las ferias financieras y de cambio de Medina del Campo, Villalón y Medina de Rioseco); en concreto, las datas de las cuentas de la Colectoría insisten en dos arrendadores principales de vacantes: Galván Bonisegna ${ }^{17}$ y Pietro Benedetto de Bosigna; ambos constan como mercaderes peritos en el cambio y ambos de nación genovesa.

Así, pues, el negocio establecido por los genoveses en torno a la Colectoría recorría todo el camino del dinero pontificio desde España hasta Roma: se

X Médicis y Adriano VI. La series contables se reinician con continuidad a partir de 15281529 y se encuentran en ASV, Camera Apostolica, Diversa Cameralia, 88, ff. 100v-104r: «Computa rev. Domine Hieronini Seledi, episcopus Vasionem, nuncii in regnis hispaniarum».

14 Giovanni Rufo de Teodole («Johannes Rufus, archiepiscopus Britonoriensis, nuntius et collector in omnibus regnis Hispania») fue nuncio y colector general desde 1506 ante Felipe I de Habsburgo, con el título de obispo de Bertinoro. Posteriormente ejerció ambos cargos durante la Gobernación de Fernando el Católico, siendo promocionado en 1520 al arzobispado de Cosenza.

15 Estas cifras manejadas por la Colectoría son de cierta importancia. En primer lugar, porque entre 1506 y 1509, ante la grave crisis política y económica soportada por los castellanos, hubo numerosas quiebras de arrendadores de rentas, que lógicamente debieron afectar a la salud financiera de la Colectoría. En segundo lugar, porque en mi opinión, aunque la documentación es de gran calidad, quizá no recogiera la totalidad de las operaciones realizadas por el nuncio-colector.

16 Por toda la bibliografía sobre este tema, véase el clásico estudio de Otte, Enrique, "Il ruolo dei genovesi nella Spagna del XV e XVI secolo”.

17 Esta familia de los Bonisegna consta ya en negocios financieros en la Corona de Aragón desde la Edad Media, especialmente en asuntos relacionados con los mercados de deuda pública (censales). 
iniciaba con el arrendamiento y gestión de los frutos de las vacantes, proseguía con la emisión de letras de cambio en las ferias castellanas contra la tesorería del nuncio-colector (los tesoreros, por lo común, también eran genoveses o florentinos) y culminaba en Roma, donde las casas bancarias liquidaban el valor de las letras a la Cámara Apostólica; obviamente, con el correspondiente beneficio.

Entre las decenas de datas que contienen las cuentas de la Colectoría de España en ese periodo de 1506-1512 he localizado un total de 64 operaciones de remesa de capitales enviadas por el nuncio-colector a Roma. Todas las operaciones registradas de envío de dinero se realizaron mediante letras de cambio. La primera de estas operaciones se efectuó el 25 de julio de 1506 (casi con toda seguridad en Valladolid) y consistió en una letra de cambio girada por el mercader Pietro Benedetto di Bosigna (entonces encargado de la tesorería de la Colectoría de España) ${ }^{18}$ contra el banco de Sebastiano Sauli en Roma, siendo el beneficiario de los 195.000 maravedíes de la operación la Cámara Apostólica ${ }^{19}$. La última de estas operaciones de cambio fue efectuada el 10 de febrero de 1513 por el factor de la casa bancaria de los Grimaldo asentado en España Agostino di Grimaldo; esta letra de cambio fue descontada en Roma en la banca de Bartolomé Doria, suponiendo una transferencia de capital para las arcas pontificias de 195.000 maravedíes ${ }^{20}$. En definitiva, el valor de los capitales transferidos desde España a Roma mediante el sistema de letras de cambio alcanzó entre 1506 y principios de 1513, según las cuentas romanas, un total de 22.305.367 maravedíes $^{21}$. En síntesis, las letras de cambio negociadas en Roma fueron las siguientes:

TABLA 3

\begin{tabular}{c|c|c|c}
\hline \multirow{2}{*}{ FECHA } & $\begin{array}{c}\text { EMISOR EN } \\
\text { CASTILLA }\end{array}$ & $\begin{array}{c}\text { DESCUENTO EN } \\
\text { ROMA }\end{array}$ & VALOR $^{22}$ \\
\hline $25-07-1506$ & Pietro B. di Bosigna & Sebastiano Sauli & 195.000 \\
$24-12-1506$ & Pietro B. di Bosigna & Paolo Sauli & 156.000 \\
$31-01-1507$ & Pietro B. di Bosigna & Juan de Saldaña ${ }^{23}$ & 124.800
\end{tabular}

18 Fue frecuente que los tesoreros de la Colectoría de España efectuaran negocios en torno a las rentas pontificias. Más aún, los depositarios generales en Roma siempre prefirieron que los tesoreros en España fueron hombres de negocio italianos peritos en las técnicas del cambio.

19 La liquidación de esta letra de cambio en ASR, Camerale I, Collettorie, 1195 (5), f. 24r.

20 Ibidem, f. 32r. La casa bancaria de Roma estaba a nombre de los Doria y otros socios genoveses no especificados en la documentación manejada.

${ }^{21}$ La liquidación final de estas letras por parte de la Cámara Apostólica de Roma en Ibidem, f. 36r.

22 Todas las cantidades, como vengo indicando, están expresadas en maravedíes.

23 Se trató de una entrega en mano a favor de la Cámara Apostólica. Desconozco si Juan 


\begin{tabular}{|c|c|c|c|}
\hline FECHA & $\begin{array}{c}\text { EMISOR EN } \\
\text { CASTILLA }\end{array}$ & $\begin{array}{c}\text { DESCUENTO EN } \\
\text { ROMA }\end{array}$ & VALOR $^{22}$ \\
\hline $15-02-1507$ & Pietro B. di Bosigna & Paolo Sauli & 312.000 \\
\hline 31-03-1507 & Pietro B. di Bosigna & Banca Grimaldo 24 & 156.000 \\
\hline $25-06-1507$ & Pietro B. di Bosigna & Banca Grimaldo & 195.000 \\
\hline $15-07-1507$ & Pietro B. di Bosigna & Banca Grimaldo & 195.000 \\
\hline 05-08-1507 & Pietro B. di Bosigna & Banca Grimaldo & 156.000 \\
\hline $15-11-1507$ & Pietro B. di Bosigna & Banca Grimaldo & 273.000 \\
\hline $31-12-1507$ & Pietro B. di Bosigna & Banca Grimaldo & 156.000 \\
\hline $17-02-1508$ & Pietro B. di Bosigna & Banca Grimaldo & 234.000 \\
\hline 07-03-1508 & Grimaldo y Vivaldo 25 & Banca Lomellino $^{26}$ & 390.000 \\
\hline $15-04-1508$ & Grimaldo y Vivaldo & Banca Lomellino & 195.000 \\
\hline $01-05-1508$ & Pietro B. di Bosigna & Banca Grimaldo & 390.000 \\
\hline 03-05-1508 & Pietro B. di Bosigna & Banca Grimaldo & 390.000 \\
\hline $15-05-1508$ & Pietro B. di Bosigna & Banca Grimaldo & 195.000 \\
\hline 25-05-1508 & Pietro B. di Bosigna & Banca Grimaldo & 490.000 \\
\hline $25-05-1508$ & Agustín de Grimaldo & Banca Lomellino & 195.000 \\
\hline $25-05-1508$ & Pietro B. di Bosigna & Banca Grimaldo & 195.000 \\
\hline $26-05-1508$ & Grimaldo y Vivaldo & Banca Lomellino & 195.000 \\
\hline 01-06-1508 & Jerónimo Bonisegna & Estefano Ginnasio & 312.000 \\
\hline 04-07-1508 & Agustín Italiano y cia & Banca Lomellino & 390.000 \\
\hline 02-08-1508 & Pietro B. di Bosigna & Banca Grimaldo & 390.000 \\
\hline 02-08-1508 & Jerónimo de Blasio & Sebastiano Sauli & 273.000 \\
\hline $20-10-1508$ & Jerónimo de Blasio & Estefano Ginnasio & 124.800 \\
\hline $31-10-1508$ & Jerónimo de Grimaldo & Banca Sauli27 & 195.000 \\
\hline 02-11-1508 & Pietro B. di Bosigna & Banca Grimaldo & 390.000 \\
\hline $15-11-1508$ & Pietro B. di Bosigna & Banca Grimaldo & 390.000 \\
\hline $10-12-1508$ & Jacobo de Grimaldo & Sebastiano Sauli & 234.000 \\
\hline 05-02-1509 & Galván Bonisegna & Estefano Ginnasio & 195.000 \\
\hline 20-02-1509 & Agustín de Grimaldo & Banca Lomellino & 195.000 \\
\hline $20-02-1509$ & Agustín de Grimaldo & Banca Lomellino & 390.000 \\
\hline $11-02-1509$ & Jerónimo de Blasio & Banca Sauli & 150.540 \\
\hline 11-02-1509 & Jerónimo de Blasio & Banca Sauli & 195.000 \\
\hline 23-04-1509 & Jacobo de Grimaldo & Banca Sauli & 156.000 \\
\hline 23-04-1509 & Cia de los Blasio 28 & Banca Sauli & 390.000 \\
\hline 01-06-1509 & Jacobo de Grimaldo & Banca Sauli & 234.000 \\
\hline
\end{tabular}

de Saldaña descontó una letra en Roma, o bien aportó directamente el capital que trajo desde España; me inclino por lo primero.

24 Siempre que mencione la banca Grimaldo estoy refiriéndome a Ambrosio y Lázaro di Grimaldo.

25 Se trataba de una compañía formada por Agustín de Grimaldo y Agustín de Vivaldo.

${ }^{26}$ Francesco y Giovanni Battista Lomellino.

27 Compañía de mercaderes formada por Vincenzo y Sebastiano Sauli.

28 Integrada por Gregorio y Jerónimo de Blasio. 


\begin{tabular}{|c|c|c|c|}
\hline FECHA & $\begin{array}{c}\text { EMISOR EN } \\
\text { CASTILLA }\end{array}$ & $\begin{array}{c}\text { DESCUENTO EN } \\
\text { ROMA }\end{array}$ & VALOR $^{22}$ \\
\hline 01-06-1509 & Pietro B. di Bosigna & Banca Lomellino & 156.000 \\
\hline $10-06-1509$ & Pietro B. di Bosigna & Banca Grimaldo & 585.000 \\
\hline 05-07-1509 & Pietro B. di Bosigna & Banca Sauli & 390.000 \\
\hline $10-07-1509$ & Grimaldo y Vivaldo & Banca Grimaldo & 390.000 \\
\hline 08-09-1509 & Grimaldo y Vivaldo & Banca Grimaldo & 195.000 \\
\hline 06-11-1509 & Grimaldo y Vivaldo & Banca Lomellino & 195.000 \\
\hline 01-12-1509 & Pietro B. di Bosigna & Sebastiano Sauli1 & 56.000 \\
\hline $25-01-1510$ & Agustín Italiano & Banca Lomellino & 195.000 \\
\hline 28-01-1510 & Grimaldo y Vivaldo & Banca Lomellino & 195.000 \\
\hline $24-07-1510$ & Grimaldo y Vivaldo & Banca Lomellino & 195.000 \\
\hline 04-08-1510 & Grimaldo y Vivaldo & Banca Lomellino & 195.000 \\
\hline $01-10-1510$ & Agustín de Grimaldo & Banca Lomellino & 195.000 \\
\hline $12-02-1511$ & Agustín de Grimaldo & Banca Grimaldo & 195.000 \\
\hline $18-10-1511$ & Agustín de Grimaldo & Banca Grimaldo & 195.000 \\
\hline $20-10-1511$ & Jacobo de Grimaldo & Banca Sauli & 195.000 \\
\hline $20-10-1511$ & Galván Bonisegna & Estefano Ginnasio & 195.000 \\
\hline 20-10-1511 & Pantaleón Lomellino & Bartolomé Doria & 195.000 \\
\hline $31-10-1511$ & Pantaleón Lomellino & Bartolomé Doria & 195.000 \\
\hline 28-11-1511 & Galván Bonisegna & Pantaleón Vieri & 195.000 \\
\hline $05-01-1512$ & Galván Bonisegna & Jacobo Venturi & 234.000 \\
\hline 20-02-1512 & Galván Bonisegna & Pantaleón Vieri & 195.000 \\
\hline 22-02-1512 & Galván Bonisegna & Pantaleón Vieri & 195.000 \\
\hline 07-03-1512 & Galván Bonisegna & Pantaleón Lomellino & 195.000 \\
\hline $14-04-1512$ & Agustín Lomellino & Andrea Gentili y cia & 234.000 \\
\hline $25-05-1512$ & Jerónimo de Blasio & Vincenzo Sauli & 195.000 \\
\hline 09-08-1512 & Galván Bonisegna & Cia Vieri y Venturi ${ }^{29}$ & 273.000 \\
\hline 31-09-1512 & Agustín Italiano & Andrea Gentili & 234.000 \\
\hline $10-02-1513$ & Agustín de Grimaldo & Bartolomé Doria & 195.000 \\
\hline
\end{tabular}

Como vemos, desde mediado el año de 1506 el principal mercader de letras de cambio fue el genovés Pietro Benedetto di Bosigna, que entonces ejercía como tesorero general de la Colectoría, además de efectuar otros negocios con el nuncio-colector como arrendador de vacantes (por ejemplo, los frutos de Segovia en 1507) ${ }^{30}$. Esta posición de Bosigna como tesorero de la Colectoría explica el alto número de cambios efectuados por el genovés: un total

${ }^{29}$ Formada por, entre otros socios, por Pantaleón Vieri y Jacobo Venturi.

$30 \mathrm{El}$ arrendamiento de los frutos y otras rentas procedentes de la Mesa Episcopal de Segovia (incluido el señorío de Turégano y su tierra) fue evaluado en 4000 ducados, que desembolsó Pietro Benedetto di Bosigna por fallecimiento el 26 de enero de 1507 del obispo Juan de Medina. 
de 22 letras con un importe de 6.145.000 maravedíes. Los principales socios de Bosigna en Roma era la banca de Ambrosio y Lázaro de Grimaldo, que poseían excelente relación con la Cámara Apostólica, quizá a través de arrendamientos de derechos pontificios. Todo ello explica que Bosigna girase a la Cámara de Roma un total de 16 letras por importe de 4.780 .000 maravedíes a través de los Grimaldo. Bosigna también se apoyó en la transferencia de los dineros de la Colectoría en la familia Sauli, una poderosa saga de mercaderes y banqueros genoveses asentados en Roma; los mejores negocios los realizó con Sebastiano Sauli. En total Bosigna negoció con los Sauli un total de cinco cambios y 1.209.000 maravedíes. Asimismo, el tesorero Bosigna negoció en 1509 una letra de cambio de 165.000 maravedíes a través de la compañía bancaria formada por Ambrosio y Lázaro de Grimaldo.

La segunda casa de mercaderes y banqueros con mayor negocio de letras hacia Roma fue la formada por Agustín de Grimaldo y Agustín de Vivaldo; la sociedad alcanzó su máximo nivel de negocio en 1508 cuando llegaron a efectuar once cambios por valor de 2.535 .000 maravedíes, aliándose en Roma con la casa bancaria de la poderosa familia de los Lomellino (sobre todo, con Francesco y con Giovanni Battista). A partir de 1509 las remesas a Roma de esta compañía tendieron a bajar; de hecho, sólo he localizado once letras por valor de 975.000 maravedíes, todas negociadas en Roma en la casa que los genoveses Grimaldo había abierto bajo la dirección de Ambrosio y Lázaro de Grimaldo. Por su parte, los Grimaldo asentados en España también participaron del negocio, aunque con operaciones de cambio modestas; todas las letras fueron negociadas en Roma a través de la poderosa familia de banqueros Sauli, bien relacionados a su vez con las familias genovesas asentadas en España.

Jacobo de Grimaldo efectuó negocios con la Colectoría por un montante de 819.000 maravedíes mediante cuatro operaciones realizadas en 1508, que fueron descontadas en Roma en la casa de Sebastiano Sauli. Jerónimo de Grimaldo, también en 1508, participó en negocios de cambio con los Sauli (en concreto, con Vincenzo Sauli) con una letra a favor de la Cámara Apostólica de 195.000 maravedíes. Ya en 1513, Agustín de Grimaldo giró una letra a Roma por valor de otros 195.000 maravedíes, que fue descontada en la casa bancaria de Bartolomé Doria.

Dentro de esta comunidad de mercaderes y banqueros italianos asentados en España a la sombra de los negocios de la Colectoría cabe destacar a los Bonisegna, siempre presentados como genoveses, aunque quizá en mi opinión de antigua ascendencia sienesa o luquesa. Los Bonisegna se asentaron en Valladolid, donde con el paso del tiempo llegaron a ser personas de calidad y señores jurisdiccionales. De lo que no cabe duda, es que los Bonisegna poseían excelentes relaciones con la Colectoría (constan como arrendadores de vacantes). Esta posición posibilitó que Jerónimo Bonisegna entrase en el negocio 
de la transferencia de capitales desde la Colectoría hacia la Cámara Apostólica de Roma en 1508, siempre con la complicidad en los negocios del descuento de la poderosa familia romana de los Ginnasio. En efecto, Jerónimo Bonisegna inauguró el negocio de letras con una de 312.000 maravedíes que la Cámara Apostólica descontó en la banca de Esteban Ginnasio.

Ahora bien, la consagración de los Bonisegna vallisoletanos como agentes de la Colectoría fue a partir de 1509 con la llegada al negocio familiar de Galván Bonisegna, que llegó a ser uno de los hombres de negocio más importantes de Valladolid en época del emperador Carlos V. Inicialmente Galván siguió apoyándose en el crédito de los Ginnasio, efectuando en ese año de 1509 dos operaciones por valor de 195.000 maravedíes cada una. En 1511 Galván Bonisegna sustituyó a los Ginnasio por los Vieri, con quienes negoció - más en concreto, con Pantaleón Vieri- tres letras de cambio emitidas en Valladolid a favor de la Cámara Apostólica por valor de 585000 maravedíes. Desde 1512 Galván Bonisegna trabajó con nuevos mercaderes-banqueros en Roma: los Venturi y los Lomellino; así, negoció con Jacobo Venturi y socios letras de cambio a favor de la Cámara Apostólica en enero de 1512 (234000 maravedíes) y agosto (otra letra de 273.000 mrs.) y con Pantaleón Lomellino otra letra (7 de marzo de 1512) evaluada en 195.000 maravedíes.

Otros mercaderes y casas de cambio menores que trabajaron en el mercado de letras entre Castilla y Roma fueron la casa de Agustín Italiano (junto con otros asociados que no constan en la documentación manejada), la de Jerónimo Blasio y la de los Lomellino de Castilla. En concreto, Italiano y compañía giró tres letras a Roma en 1508 por un montante de 585.000 maravedíes, que fueron negociadas por la Cámara Apostólica ante la banca de los Lomellino (Francesco y Giovanni Battista), así como (ya en 1512) otra letra por importe de 234.000 maravedíes que fue descontada ante el banquero romano Andrea Gentili. Jerónimo Blasio sólo efectuó operaciones de cambio en 1508, aunque su actividad fue enorme: seis letras y un volumen de negocio de 1.328.340 maravedíes; las letras fueron negociadas en Roma ante las casas bancarias de Estefano Ginnasio y los Sauli (Vincenzo y Sebastiano). Por último, los Lomellino asentados en Castilla (Pantaleón y Agustín) emitieron tres letras contra las casas de descuento en Roma: dos letras por un total de 390.000 maravedíes en la banca de los Doria y otra de 234.000 pagada a la Cámara Apostólica por la compañía de Andrea Gentili y socios.

OTRAS FÓRMULAS DE TRANSFERENCIA: PAGO DE CRÉDITOS Y DE MERCANCÍAS Y SERVICIOS A MEDIADOS DEL SIGLO XVI

Como se ha visto, la llegada a España de Giovanni Poggio en 1529 supuso la potenciación de la Colectoría, tanto en sus sistemas organizativos y defensa 
de sus derechos, como en el perfeccionamiento de los mecanismos de transferencia de los capitales obtenidos en España hacia la Cámara Apostólica de Roma. En este sentido, el periodo del colector Poggio (1529-1546) vino caracterizado por dos fenómenos: el asentamiento definitivo del tráfico de letras entre España y Roma y, más en concreto, la incorporación de los ingresos de la Colectoría de España en el programa de financiación del crédito de la Cámara Apostólica, esto es, el crédito que la tesorería pontificia obtenía de los banqueros italianos a partir del aval de los ingresos de España. Vayamos por partes.

En cuanto al primer aspecto (la consolidación del mercado de letras de cambio entre Castilla y Roma) la documentación es obviamente abundantísima. Como un ejemplo más, en las cuentas romanas de los mercaderesbanqueros Boni y Ubaldini ${ }^{31}$ constan ingresos de España por valor de 7.159.112 maravedíes, que fueron cambiados en ducados (18.812) y posteriormente negociados en escudos romanos (19.282). Las cuentas de los Boni y los Ubaldini, que trabajaban en Roma para la Cámara Apostólica, reflejan perfectamente la enorme densidad de los negocios financieros desarrollados por el colector Giovanni Poggio desde España. La precisión de estas cuentas es tal que nos permite conocer también el precio pagado por la Colectoría por el cambio de maravedíes en ducados; así consta el tipo de cambio, que oscilaba entre 377 y 379 maravedíes por ducado ${ }^{32}$. Posteriormente el colector ordenaba que se pagase a los banqueros flamencos Affaitadi, en tanto estos mercaderes representaban, como agentes, los intereses de varios banqueros romanos que habían prestado dinero a la Cámara Apostólica, y ésta ordenaba que se liquidasen los créditos pendientes en Roma a partir de los dineros de la Colectoría de España. Así los Affaitadi remitieron los 18.812 ducados castellanos utilizando las ferias de Villalón y la feria de mayo en Medina del Campo de 1548. En síntesis, los banqueros Affaitadi asentados en Valladolid recibían los ingresos de la Colectoría de España y remitían el dinero a Roma mediante letras de cambio negociadas en las ferias financieras castellanas; posteriormente, se liquidaban en las casas bancarias de Roma y los acreedores de la Cámara Apostólica (que habían autorizado las operaciones de los Affaitadi en Castilla) percibían los capitales e intereses de sus créditos.

31 ASR, Camerale I, Giustificazioni di Tesoreria, 2, 2, ff. 7v-8r, asiento contable del dinero remitido por el colector Poggio desde España a la Cámara Apostólica entre 1547 y 1549.

32 Ibidem, f. 8r, donde, por ejemplo, se asienta que el ingreso de 1.137 .000 maravedíes procedentes de los Pinelo se contabilizaron en ducados al valor de 379 maravedíes por ducado (17 de julio de 1548); un ingreso de noviembre de ese mismo año por valor de 1.580 ducados cotizó a 378 maravedíes por ducado. En definitiva, una cosa era el cambio oficial (375 maravedíes por ducado) y otra muy diferente el cambio real según las leyes de los mercados. 
Estos mecanismos financieros de remisión de sumas entre la Colectoría de España y la Cámara Apostólica en Roma fueron esenciales para sostener el alto grado de endeudamiento que contrajo la Cámara bajo el aval de la rentas españolas. Este fue el destino de decenas de miles de ducados que salieron de España para nutrir el crédito pontificio. Además, fue un negocio a espaldas de los castellanos, pues sólo benefició a los banqueros italianos.

La razón de todo ello era muy simple: el sistema hacendístico (especialmente el régimen de pagos) de la hacienda pontificia estaba centralizado en un depositario general que tenía como principal misión la de garantizar que las cuentas pontificias gozasen de liquidez. Por ello, el cargo de depositario general de la Cámara Apostólica siempre estuvo ocupado por un banquero del máximo prestigio (esto es, capaz de sostener el crédito y el sistema de pagos pontificio). Durante la época de Giovanni Poggio los principales depositarios fueron los florentinos Strozzi y los genoveses Grimaldo. Ello explica que todos los movimientos financieros surgidos en el entorno de la Colectoría se encontrasen bajo el monopolio de banqueros italianos residentes en Castilla, todos agentes y factores de las grandes bancas conectadas con los negocios de la Cámara Apostólica ${ }^{33}$.

El primer depositario general en Roma de la época del colector Poggio fue el mercader florentino Filipo Strozzi. La banca Strozzi ofrecía continuamente liquidez al sistema de pagos del papa Clemente VII Médicis mediante créditos que, obviamente, debía devolver la Cámara Apostólica. Constan en las cuentas españolas varias de esas operaciones. Por ejemplo, en 1531 la Cámara adeudaba 21.640 ducados a Filipo Strozzi; éste obtuvo 8.272 ducados de las rentas pontificias de España a través de sus agentes en Valladolid, donde se situaba una delegación bancaria de la familia bajo el control de Renaldo Strozzi. En 1535 se hizo otra operación similar: Renaldo Strozzi obtuvo de Poggio 11.104 ducados a cuenta de un crédito de 25.000 ducados otorgado en Roma por Filipo Strozzi a la Cámara Apostólica ${ }^{34}$. Junto a Renaldo, también se citan en negocios próximos a la Colectoría a Julio y Lorenzo Strozzi, así como Francesco Corsini.

Después de los Strozzi la depositaría general de Roma fue gestionada por uno de los banqueros más poderosos de Europa en ese momento: Ansaldo de Grimaldo, depositario del Papa y banquero del emperador Carlos V (esto es, «a Dios y al César»). El esquema en España de Grimaldo fue el mismo que el de Strozzi: utilizar la red que su propia familia poseía en España: Gaspar, Bernabé, Estefano y Antonio de Grimaldo, apoyados por otros mercaderes

33 CARRETERO ZAMORA, LXXVIII (Buenos Aires, 2004): 120.

34 ASR, Camerale I, Collettorie, 1198, 2 B, «Item, deve la Camera Apostolica... a Renaldo Strozzi a conto delli 25.000 ducati assignati sopra questa Collettoria a Philippo Strozzi...». 
genoveses, caso de los Salvago ${ }^{35}$. Estos Grimaldo efectuaron importantes operaciones de miles de ducados contra la Colectoría, casi todas capitaneadas por Bernabé en nombre de Ansaldo ${ }^{36}$.

En definitiva, una vez más, contra las rentas de la Colectoría de España se estaban negociando importantes operaciones de crédito efectuadas en Roma: la Cámara Apostólica tomaba dinero en Roma y ordenaba su devolución con cargo a los ingresos españoles. La mayoría de estas operaciones se enmarcaron obviamente en las ferias financieras de Villalón, de mayo y de octubre en Medina del Campo y en menor medida en Medina de Rioseco («Ruyseco», en el lenguaje romano). Por ejemplo, en el transcurso de la feria financiera de Villalón de 1543 se efectuó contra las rentas de la Colectoría un pago a Benvenuto Olivieri (banquero de Roma) ${ }^{37}$, que representaba los intereses de los herederos del banquero de Bolonia Carlo Cataneo. Éste había prestado al Papa 5.000 escudos. El final de la operación fue dirigida por los Strozzi de Valladolid: ellos ejercieron de agentes de Olivieri y éste liquidó con sus clientes (los herederos de Carlo Cataneo). En definitiva, un crédito tomado en Bolonia acabó siendo devuelto en Villalón.

En 1545, en Medina del Campo, se produjeron una serie de pagos contra la Colectoría en referencia a operaciones de crédito efectuadas por la Cámara Apostólica en Roma. El 9 de diciembre de 1545 Giovanni Pietro y Giovanni Bavtista Affaitadi y compañía, como agentes del banquero romano Olivieri, percibieron 6.000 ducados. Entre diciembre de 1545 y enero de 1546 los citados Affaitadi, en funciones de agentes de prestamistas de la Cámara Apostólica, recibieron pagos como procuradores de las compañías bancarias en Roma de Hieronimo Ubaldini y Bindo Altovite, en tanto los agentes de Renaldo Strozzi efectuaban lo mismo respecto de los intereses de la también compañía de crédito sita en Roma del banquero Alejandro Bartoli. Los propios Affaitadi asentados en Castilla cobraron (15 de abril de 1546) 530 ducados que habían adelantado al arzobispo de Rossano, cuando ejerció la nunciatura cerca del emperador Carlos $\mathrm{V}^{38}$. No obstante, la mayor operación de crédito contra la Colectoría en época del colector Giovanni Poggio se realizó en 1546, cuando los Affaitadi ejercieron como agentes de un grupo de banqueros romanos que habían prestado 25.000 ducados de oro a la Cámara Apostólica: el 18 de ma-

35 CARRETERO ZAMORA, LXXVIII (Buenos Aires, 2004): 121.

36 Por ejemplo, una operación de 1539 por 20000 ducados negociada por Bernabé Grimaldo en España, bien para dotar de fondos a la Cámara Apostólica en Roma, o bien devolver un crédito a los Grimaldo, está bien descrita en ASR, Camerale I, Collettorie, 1198, $2 \mathrm{~B}$, «Et piu si pagano in feria de maggio de Medina del Campo alli agenti e respondenti del depositario [Ansaldo de Grimaldo]... per diversi ordine de Sua Santita et di monsignore tesorero generale vinti millia ducati».

37 Sobre los negocios de Olivieri véase el excelente estudio de GUIDI BRUSCOLI, 2000.

38 CARRETERO ZAMORA, LXXVIII (Buenos Aires, 2004): 
yo de 1546 el cardenal camerario dispuso que la deuda fuese liquidada contra las rentas de España ${ }^{39}$. En síntesis, las principales operaciones de crédito de la época de la Colectoría de Giovanni Poggio fueron:

TABLA 4

\begin{tabular}{c|c|c|c}
\hline AÑO & BENEFICIARIO & CONCEPTO & DUCADOS \\
\hline 1531 & Juan B. Minuroli & A cuenta de 8.000 ducados & 5.368 \\
1531 & Renaldo Strozzi & A cuenta de 21.640 ducados & 8.272 \\
1535 & Renaldo Strozzi & A cuenta de 25.000 ducados & 9.000 \\
1536 & Bernabe Grimaldi & A cuenta de la depositaria & 16.000 \\
1536 & Renaldo Strozzi & A cuenta de 17.000 ducados & 11.104 \\
1536 & Francesco Corsini & A cuenta de 17.000 ducados & 7.500 \\
1537 & Bernabé Grimaldi & Por orden de Ansaldo Grimaldi & 5.647 \\
1539 & Agentes Grimaldi & Para el depositario general & 20.000 \\
1541 & Esteban Salvago & Para la depositaría general & 10.000 \\
$1542-45$ & Carlo Cataneo & Devolución de un préstamo & 6.015 \\
$1542-45$ & Bernabé Grimaldi & Para la cuenta del depositario & 5.266 \\
1546 & Cia.Affaitadi & Cantidad adeudada a Olivieri & 6.000 \\
1546 & Cia. Affaitadi & Varios banqueros romanos & 4.958 \\
1546 & Cia. Affaitati & Varios banqueros romanos & 12.162 \\
\hline
\end{tabular}

Además de créditos, la Colectoría de España también transfirió a Roma importantes cantidades por el pago de compra de mercancías y servicios en beneficio del papa y de la Curia. Por ejemplo, en 1539 la Colectoría asentó más de dos mil ducados en correos y viajes ${ }^{42}$, destacando los gastos de la visi-

39 ASR, Camerale I, Collettorie, 1198, 2 B, «Piu deve dare ducati dodici mila cento sessanta dua pagati a di otto de decembre (1546) alli detti Giovanni Battista et Giovanni Pietro Affaitadi et compagni, come procuratori di Sebastiano Montaguto, Luigi Rucelay, Brido Altoviti, Thomasso Cavalcanti, et Giovanni Giraldi, Pietro Antonio, et Aleman Bandim, Hieronymo Ubaldini, Thobia Pallavicino, Luca Giustiniano et Baldessare Olgiati, mercanti di Roma, a conto di uno assegnamento di venticinque mila ducati d’oro dato loro sopra la Collettoria di Spagna, come appare per un mandato camerale di 18 di maggio 1546».

40 Los Affaitadi eran también agentes en Medina del Campo de Benvenuto Olivieri y compañía de Roma.

41 Concretamente, las compañía bancarias de Thomasso Cavalcanti, Giovanni Giraldi y Hieronimo Ubaldini.

42 ASR, Camerale I, Collettorie, 1198, 2 B, ff. 67-74: «Ragione et conto ch da Joan Poggio, nuntio e collettor, per sua Sanctita et sua Camera Apostolica, ne regni de Hispana per 
ta a España del cardenal Farnese, que supuso un desembolso de quinientos ducados, o los numerosos correos a Roma, que venían a costar una media en torno a los 150 ducados $^{43}$. Más onerosas fueron las cantidades consumidas en el pago de tapices, alfombras, corambres, caballos y otros productos de lujo (unos adquiridos en España, otros en Flandes... todos con destino a Roma). En 1531 el colector de España tuvo que asentar como gasto la financiación de la compra de tapices en Flandes para disfrute del Papa Clemente VII Médicis; la compra de los tapices en Flandes la realizó hacia 1527 o 1528 un mercader de Lucca llamado Juan Bautista Minuroli, que evaluó la operación en 21.640 ducados, de los cuales 8.272 fueron obtenidos de España (la operación la realizó el vallisoletano Renaldo Strozzi). En 1532 y 1533 más tapices para Roma: 7.000 ducados pagados a los flamencos Juan de Borgoña y Hugo Moreau. En 1532 alfombras de las monjas de Alcaraz, muy estimadas por el papa y los cardenales de la Curia, especialmente del cardenal Alejandro Farnese ${ }^{44}$, otros mil ducados en caballos para el papa y el dicho Farnese en las cuentas de 1535 y $1536^{45}$ y, en fin, en 1544 otros 800 ducados en finos cordobanes, muy apreciados también por los pontífices ${ }^{46}$.

lo administrato et recuperato delli emolumenti pertinenti alla Santita di N. Signore et sua Camera Apostolica, de primo di gennaro 1539 per tutto decembre del detto anno».

43 Por ejemplo, un correo que se mandó desde Toledo a Roma para anunciar la muerte de la emperatriz Isabel de Portugal costó 140 ducados (ibidem, «Et piu tre de maggio cento quaranta ducati che si dettero a Piloya, corrier che parti in diligentia de Toledo per Roma, con l’aviso de la morte de la imperatrice»).

44 Ibidem, «... Alli monache de Alcharaz, per mano di Gonsalvo Darenaper, far li tapeti ordinati di Papa Clemente et hora ne finito uno grande qual esere molto bello».

45 Éste pago de mil ducados en caballos en ibidem, 2 B, ff. 33-46: «Ragione et conto che da mons. Joan Poggio nuntio et collettor per sua Santità et sua Camera Appostolica ne regni de Hispania per lo administrato et recuperato delli emolumenti pertinenti alla Santità di Nostro Signore et sua Camera Appostolica poi dell ultimi conti dati a di primo di gennaro 1535 sino a di primo di gennaro del anno 1537».

46 Esta afición por los cueros finos cordobeses debió ser común a todos los pontífices. Así, a comienzos del siglo XVII, el nuncio-colector Domenico Carafa puso especial empeño en suministrar a Pablo V y su nepote el cardenal Scipio Borghese los mejores guadamecíes, comisionando a Luis de Góngora como responsable de las compras en Córdoba: «Guadameçíes que se han mandado haçer por serviçio de su santidad en Córdova... en 12 de henero de 1611 años 1.300 reales que Bautista Serra hiço pagar en Córdova a D. Antonio de Quiñones, por otros tantos que havía pagado de su orden Luís de Góngora a Juan Carrillo, guadamaçilero, en quenta de los que haçe por su santidad... que de Córdova se enviaron a Alicante, para embarcallos por a Roma» (ibidem, 1200, expte. M.). 


\section{LA TESORERÍA DE LA COLECTORÍA DE ESPAÑA Y SUS SISTEMAS DE TRANS- FERENCIA A ROMA (1577-1612)}

En las últimas décadas del siglo XVI la Colectoría de España observó importantes transformaciones, sobre todo en una clara tendencia hacia la centralización de todas sus funciones. Ello fue evidente en un doble aspecto. En primer lugar, porque todas las funciones tendieron a concentrarse en la corte de Madrid, donde en torno a la Nunciatura la Colectoría edificó un complejo entramado burocrático fortísimamente centralizado: colector general, letrado, secretario, fiscal, tesorero general, notario apostólico, etc.; en dicho entramado, una de las funciones más beneficiadas fue la tesorería general, que centralizó todos los ingresos y pagos de la Colectoría a través de una caja única residente en Madrid. En segundo término, esa centralización en la corte de los Habsburgo se vio favorecida por la definitiva unificación de los cargos de nuncio y de colector general que, hasta entonces, salvo contados periodos, habían mantenido identidad propia. La creación, pues, del cargo de nunciocolector optimizó el papel de la Colectoría, tanto en su vertiente institucional ante la Corona y el Consejo Real, como en sus aspectos financieros con una mayor agilidad en la transferencia de fondos entre España y Roma.

De lo que no cabe duda es que el movimiento de dinero, tanto de la subcolectorías de los obispados con el colector en Madrid, y de éste con la Cámara Apostólica, se efectuaba mediante letras de cambio. Por ejemplo, cuando monseñor Castagna (el futuro papa Urbano VII) fue nombrado colector ${ }^{47}$ en julio de 1572 entre la documentación que recibió del subcolector general Ranuccini, sobre los asuntos pendientes de la Colectoría, constaban dos letras de cambio giradas por el subcolector de Segorbe a cuenta de los frutos de la vacante de ese obispado por valor de 1.165 castellanos $^{48}$, que serían efectivas en la feria de octubre en Medina del Campo de ese año de $1572^{49}$.

Hacia Roma el ritmo de envío de las letras de cambio dependía, tanto de la eficacia en el pago de los arrendamientos de las vacantes, como del mayor o menor número de fallecimientos de obispos. Pero, sobre todo, los colectores tendieron a buscar arrendadores fiables; por ello, la crisis de los genoveses afectó sobremanera al flujo de letras de cambio hacia Roma. A fines de 1577 el colector Canobio se quejaba al cardenal de Como (alto responsable de la Cámara Apostólica en Roma) que no podía mandar más letras por «ruina et poco credito dei genovesi ${ }^{50}$, aunque precisaba la solvencia de algunos arren-

47 Giovanni Battista Castagna ya ejercía como nuncio en España por breve de Pio IV del 20 de agosto de 1565 (ASV, Segretaria di Stato, Spagna, 2, f. 72).

48 En ese momento el castellano cotizaba a razón de 485 maravedíes.

49 ASV, Segretaria di Stato, Spagna, 2, ff. 98-99 y 103.

50 Ibidem, Spagna, 12, f. 104 ( Carta del colector Canobio al cardenal de Como, 12 de octubre de 1577). 
dadores españoles que empezaban a sustituir a los maltrechos genoveses en los negocios de la Colectoría. Ello explicaba que Canobio prefiriera arrendar los frutos de la vacante de Ávila al futuro obispo por una cantidad menor, aunque segura ${ }^{51}$, o que se deshiciera en elogios del arrendador de Medina del Campo Juan de Escobar («mercante di assai buon credito et honeste fortune»).

No obstante, el verdadero ritmo de los envíos de dinero a Roma venía en buena medida marcado por la mejor o peor salud de los prelados españoles, y su escasa disponibilidad a entregar el alma a la benevolencia de San Pedro. Ello daba lugar a macabras relaciones epistolares entre Roma y la Colectoría de España. A finales de 1587, por citar un ejemplo, el cardenal Montalto se quejaba al colector Passamonti de que no llegaban suficientes letras de cambio a la Cámara Apostólica. Passamonti, con cierta dosis de humor negro, matizó a Roma que la razón del escaso flujo de dinero era la extraordinaria vitalidad de los prelados españoles que no morían a buen ritmo: «Tutti questi vescovi stanno in una grandissima sanità, et sono già nove mesi che non è morto più che uno»52. Sobre el cardenal de Toledo (D. Gaspar de Quiroga y Vela) el colector señalaba que había estado a punto de morir, pero que había revivido («Non li mando dinari perche non ce ne sono. Il cardinale di Toledo ha fatto dubbitare della vita sua, ma vogliono che si sia rihavuto») ${ }^{53}$. Pese a ello, el volumen de letras de cambio desde España a Roma fue siempre incesante. Veamos la contabilidad del mismo colector Passamonti.

Solamente desde noviembre de 1587 hasta principios del mes de diciembre de 1589 (esto es, poco más de dos años), Passamonti remitió a Roma dieciocho letras de cambio por valor de 111.000 ducados, todas giradas desde Madrid por la banca de los Pinelli y los Gentile ${ }^{54}$. Esta cifra era neta, habiéndose previamente descontado todos los gastos de gestión de la Colectoría y otros muchos pagos menudos. En síntesis, el ritmo de transferencia fue el siguiente:

51 Ibidem, ff. 190-191, «Io ho arrendato al signore vescovo di Pati, nominato alla chiesa d`Avila, i frutti di quella chiesa con la migor sigurta chi sia, qui in corte dal Litta in fuori per 12.000 ducati, da altri non trovano più di 12.500 ”. Subrayaba que había preferido entregar el arrendamiento por 12.500 al obispo porque "era un prelado gentilisimo y ofrecia gran seguridad».

52 Ibidem, Spagna, 36, f. 44.

53 Ibidem, f. 43, carta del colector Passamonti al cardenal Montalto (Madrid, 17 de septiembre de 1588). Tanto Passamonti, como Montalto, tuvieron que esperar a 1594 para que el cardenal Quiroga decidiera pasar a mejor vida.

54 Todo el movimiento de letras en ASR, Camerale I, Depositeria Generale, 1821 («Libro terzo della Dipositeria Generale della Reverenda Camera Apostolica, l`anno 1587»). 
TABLA 5

\begin{tabular}{|c|c|}
\hline FECHA DE LA LETRA & IMPORTE DE LA LETRA \\
\hline $\begin{array}{l}\text { - } 14 \text { de noviembre de } 1587 \\
\text { - } 12 \text { de diciembre de } 1587 \\
\text { - } 9 \text { de enero de } 158855 \\
\text { - } 6 \text { de febrero de } 1588 \\
\text { - } 5 \text { de marzo de } 1588 \\
\text { - } 2 \text { de abril de } 1588 \\
\text { - } 25 \text { de junio de } 1588 \\
\text { - } 23 \text { de julio de } 1588 \\
\text { - } 15 \text { de octubre de } 1588 \\
\text { - } 12 \text { de noviembre de } 1588 \\
\text { - } 7 \text { de enero de } 1589 \\
\text { - } 1 \text { de abril de } 1589 \\
\text { - } 27 \text { de mayo de } 1589 \\
\text { - } 24 \text { de junio de } 1589 \\
\text { - } 22 \text { de julio de } 1589 \\
\text { - } 19 \text { de agosto de } 1589 \\
\text { - } 14 \text { de octubre de } 1589 \\
\text { - } 9 \text { de diciembre de } 1589\end{array}$ & 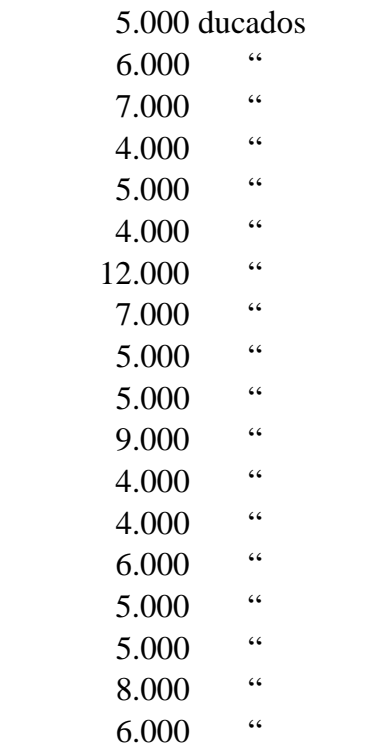 \\
\hline TOTAL & 111.000 ducados \\
\hline
\end{tabular}

A principios del siglo XVII, con la absoluta centralización de todas las cuentas en manos del tesorero general de la Colectoría (primero un Pallavicini, después un Serra ${ }^{56}$ ), el ritmo de los envíos tendía a concentrarse en uno o dos por trimestre. Por ejemplo, en 1609 las cuentas de la Depositaría de la Cámara Apostólica de Roma ${ }^{57}$ asentaron cuatro ingresos procedentes de España: 9.973 ducados en febrero, otros 11.968 en mayo, 8.000 en julio y finalmente otros 14.960 ducados en octubre. Todo este flujo de dinero se reali-

55 En esa misma fecha debió emitirse otra letra (u otro instrumento de pago) de 4000 ducados en beneficio de la Compañía de Jesús para ayuda a los establecimientos de la orden en Japón. Era una cantidad anual que había sido concedida por el Papa Gregorio XIII sobre las rentas del arzobispado de Sevilla.

56 No casualmente este tesorero de la Colectoría era hermano de Giacomo Serra, cardenal creado por Pablo V Borghese en 1511 (titulo de S. Giorgio in Velabro y desde 1615 cardenal titular de la bellísima iglesia romana de Santa María della Pace) y alto responsable de la Cámara Apostólica en Roma. Más datos de los negocios de estos Serra en España en CARRETERO ZAMORA, 2011: 250.

57 ASR, Camerale I, Depositeria Generale, 1866, «Libro della Dipositeria Generale di Papa Paolo Quinto dell `anno 1609». 
zaba mediante letras de cambio, incluidas las liquidaciones de bienes procedentes de los espolios ${ }^{58}$.

Una parte de estas letras de cambio remitidas desde España se ingresaban directamente en las arcas de la Cámara Apostólica de Roma. No obstante, como venía siendo habitual, otros muchos cambios de España fueron desviados al pago de créditos ante los banqueros acreedores del papa o de miembros de la Curia. Los ejemplos serían muy numerosos; así en octubre de 1577 el colector Canobio, por orden del tesorero general de la Cámara en Roma (monseñor Ludovico Taverna) tuvo que entregar a Giovanni Battista Litta, que era agente del banquero romano Olgiati, letras por un total de $10.000 \mathrm{du}-$ cados que la Cámara Apostólica debía al citado Olgiati59. De igual manera, por vía de letra de cambio, cobraba sus emolumentos en Roma el cardenal camerario (que tenía derecho a un veinteavo de todos los ingresos de la Colectoría) ${ }^{60}$, así como las numerosas pensiones adscritas a los cardenales de la Curia contra los obispados españoles ${ }^{61}$.

El sistema de remisión a Roma de las letras de cambio se encuentra perfectamente descrito en las cuentas de la Cámara Apostólica de Roma y en la correspondencia entre los nuncios-colectores y el cardenal camerario: las letras eran enviadas por triplicado para asegurar la fiabilidad del sistema; una vez negociadas ante los banqueros romanos a quienes iban dirigidas, las cantidades eran ingresadas en la depositaría general ${ }^{62}$. El coste de los cambios era

58 En ibidem, Camerale I, Collettorie, 1200, expte. M, consta un asiento sobre la remisión a Roma de una letra de «246.092 maravedíes, valor de 500 escudos de las 8 estampas y 500 julios, de que dio letra a monseñor ilustrísimo para Roma sobre Lorenzo Saboto y Ambrosio Poçobenelo a pagar a la persona que mandase su santidad, y son por la propria cantidad que se havía cobrado de los testamentarios del cardenal de Guevara por el anillo; dar dineros remetidos: 246.092 maravedíes».

59 ASV, Segretaria di Stato, Spagna, 12, f. 97.

60 Ibidem, Spagna, 36, f. 50, carta del cardenal camerario Gaetano a Passamonti (Roma, 3 de octubre de 1588), donde le pide que le remita su porcentaje sobre los ingresos de la Colectoría de España: «Che Nostra Santità havea conceduto al mio camorlengato la vigesima delle portione che tocca al collettore di Spagna, come é stato in altri tempi; et perch io presi il possesso del mio officio à 12 di settembre del 87, dicevo a V.S. che si fusse contentata di rimettermi quanto prima tutto quello che mi toccava per la sudetta vigesimada».

61 Ibidem, Spagna, 336, ff. 37-38, carta de la Cámara Apostólica de Roma al nunciocolector Decio Carafa (Roma, 10 de diciembre de 1609) solicitánole que defendiera las pensiones del cardenal Sauli (1.000 ducados sobre Sevilla y otros 1.000 sobre Segorbe): «Non havendo il signore cardinale Sauli conseguito finequito le sue pensione sopra le chiese di Siviglia et Segorvei».

62 Una buena síntesis en ASR, Camerale I, Depositeria Generale, 1809, «Secondo libro della Dipositeria Generale della Reverenda Camera Appostolica, l`anno 1573», f. 140v (23 de marzo de 1574), «...rescossi con ordine del reverendisimo monsignore thesorero generale da Boschi e Gavotti disse per ducati 4.000 di mrs. 375 pagati dal protonotario Confalonero da Lazaro Doria in Madrid ad 27 di genaro passato». 
muy elevado; de hecho, las quejas desde Roma era constantes, especialmente por los cardenales y obispos de la Curia beneficiarios de pensiones en España. La misma Cámara Apostólica solicitó continuamente del colector que pusiera orden en el precio de los cambios ${ }^{63}$.

\section{Bibliografía}

Carretero Zamora, Juan Manuel, "La Colectoría de España en época de Carlos V: cuentas del nuncio y colector general Giovanni Poggio (1529-1546)", Cuadernos de Historia de España, LXXVIII (Buenos Aires, 2004): 103-135.

Carretero Zamora, Juan Manuel, "In bene della Cristianità e della sancta religione: las ayudas financieras del pontificado a los príncipes católicos (1525-1717)”, en Alberto Marcos Martín (ed.), Hacer historia desde Simancas. Homenaje a José Luis Rodríguez de Diego, Valladolid, Junta de Castilla y León, 2011; 243-258.

Guidi Bruscoli, Francesco, Benvenuto Olivieri. I mercatori fiorentini e la Camera Apostolica, Firenze, Leo S. Olschki, 2000.

Otte, Enrique, "Il ruolo dei genovesi nella Spagna del XV e XVI secolo”, en Aldo de Maddalena y Hermann Kellenbenz (eds.), La Repubblica internazionale del denaro tra XV e XVI secolo, Bolonia, 1986; 17-56.

Recibido: 21-11-2010

Aceptado: 01-07-2011

63 ASV, Segretaria di Stato, Spagna, 9, f. 152v, donde constan las protestas del secretario de la Cámara Apostólica de Roma al colector en Madrid Ormaneto (3 de julio de 1576). 